\title{
Fundamentos éticos e marxismo: influências das obras de Karl Marx e Antônio Gramsci para o Serviço Social
}

\author{
Ethical Foundations and Marxism: influences of the works of Karl Marx and Antônio Gramsci \\ for Social Work
}

Salyanna de Souza Silva*

\begin{abstract}
Resumo
O presente artigo visou realizar um estudo bibliográfico a partir das obras de Karl Marx e Antonio Gramsci no sentido de identificar as contribuições críticas de tais autores para o debate dos fundamentos éticos do Serviço Social. Ao desmitificar o equívoco de que as obras marxianas e marxistas não se debruçaram sobre o estudo da ética, foi identificado quer seja Marx quanto Gramsci, fazem uma leitura ética acerca da economia política, do Estado, da sociedade, da (re)produção de desvalores e da alienação nas relações sociais capitalistas. Para o marxista sardo a "filosofia da práxis" deve voltar-se principalmente, mediante o partido político, para realização de uma reforma intelectual e moral e para formação de uma vontade coletiva nacional-popular, enquanto elementos no processo de transformação societária.
\end{abstract}

Palavras-chave: Fundamentos éticos. Serviço Social. Filosofia da práxis.

\begin{abstract}
This article aims to conduct a bibliographic study based on the works of Karl Marx and Antônio Gramsci in order to identify the critical contributions of such authors to the debate on the ethical foundations of Social Work. By demystifying the misconception that Marxian and Marxist works did not focus on the study of ethics, we identified that it is Marx and Gramsci who make an ethical reading about political economy, the State, society, the (re) production of devaluations and the alienation in capitalist social relations. For the Sardinian Marxist, the "philosophy of praxis" must focus mainly, through the political party, for the realization of an intellectual and moral reform and for the formation of a national-popular collective will, as elements in the process of societal transformation.
\end{abstract}

Keywords: Ethical foundations. Social service. Philosophy of praxis.

\footnotetext{
*Assistente Social. Doutorado em Serviço Social pela Università degli Studi Roma Tre (Roma/Itália). Pós-Doutora em Serviço Social pelo Mestrado Acadêmico de Serviço Social, Trabalho e Questão Social (MASS) da Universidade Estadual do Ceara (UECE). Professora Adjunta do Departamento de Serviço Social da Universidade Federal do Espírito Santo (UFES).
} 
Introdução

No âmbito do processo de erosão das bases teóricas, metodológicas e políticas do Serviço Social tradicional, iniciado no Brasil nos anos 1970, as primeiras aproximações ao "marxismo" se deram acompanhando o Movimento de Reconceituação ${ }^{2}$ da profissão na América Latina. Nesse momento germinal, tal perspectiva crítica trazia muitos dos enganos da II Internacional, portando um viés economista e eclético, sem recursos às obras de Karl Marx e demais autores(as) marxistas.

De caráter equivocado e superficial (BARROCO, 2003; NETTO, 2002), a adoção inicial ao marxismo levou a uma postura que ora priorizava a militância, o voluntariado, o sacrifício, em detrimento do reconhecimento do Serviço Social como uma profissão reconhecida e legitimada pela sociedade (BARROCO, 2003); ora realizava uma leitura determinista e estruturalista da realidade.

É mister sinalizar a presença de ambiguidades da compreensão da teoria revolucionária seja na própria esquerda brasileira que no âmbito Serviço Social. Sob tal argumento sinalizou-se à relevante pesquisa de Consuelo Quiroga (1991) realizada em 1989. Para autora, além das próprias limitações no acesso as obras de Marx, algumas vezes limitado à leitura de manuais; deu-se também uma verdadeira "invasão positivista no marxismo" o que reverberou na sua compreensão meramente epistemológica,-reduzido tanto a uma mera produção do conhecimento, o que tende a ocultar sua dimensão revolucionária e

\footnotetext{
${ }^{2}$ No contexto dos anos de 1960 e 1970 iniciou-se um processo intitulado por Netto (2002) de "erosão do Serviço Social tradicional", este tratou-se de um fenômeno circunscrito à América Latina de contestação às tradicionais práticas profissionais pautada na revisão crítica de suas bases teóricas e metodológicas. O Serviço Social indagava-se sobre o exaurimento das organizações governamentais, das políticas sociais (Welfare State) e dos próprios valores de "integração" capitalistas burgueses (NETTO, 2002, p. 143). Nessa dinâmica o Movimento de reconceptualização (ou reconceituação) do Serviço Social Latino-Americano surge como expressão de crítica e renovação da profissão. Mesmo com curta duração (apenas uma década - 1965 a 1975), a causa de motivos externos (repressão das ditaduras presentes nos países do Cone Sul) e internos (heterogeneidade de posições e projetos entre seus participantes); a reconceptualização deixou como legado para o Serviço Social LatinoAmericano uma aproximação seja à tradição marxista que as demais experiências profissionais do continente. Pesquisas mais recentes sinalizam para influência ímpar do Centro Latino-Americano de Trabalho Social (CELATS), criado em 1974, que tinha como objetivo "contribuir com as debilidades identificadas na formação e desenvolvimento de temáticas centrais para o Serviço Social no subcontinente: investigação, capacitação, comunicação e modelos práticos" (BRAVO et al., 2019, p. 65). Destaca-se ainda uma relação entre o supracitado centro e a realização do Congresso da Virada - III Congresso Brasileiro de Serviço Social (CBAS) em 1979 (BRAVO et al., 2019, p. 66).
} 
transformadora; quanto ao "entendimento do desenvolvimento da sociedade como produto reflexo da infraestrutura sobre a superestrutura, supervalorizando a determinação econômica." (QUIROGA, 1991, p. 11).

Somente no final da década de 1980, acompanhando o movimento de redemocratização, ampliação dos direitos civis/sociais e reorganização da esquerda no Brasil, o Serviço Social se aproxima das obras completas de Marx, bem como de outros autores(as) marxistas como por exemplo o húngaro György Lukács e o italiano Antonio Gramsci ${ }^{3}$, este último contribuiu com suas reflexões no âmbito da política, da cultura e da ideologia, por meio de categorias como o Estado, sociedade civil e política, hegemonia, filosofia da práxis, o que contribui para a "superação da perspectiva estruturalista de Althusser, permitiu repensar a compreensão meramente instrumental do Estado e dos vínculos entre política social, questão social e profissão" (SIMIONATTO, 2018, p. 90).

Foi possível, conforme afirma Barroco (2003), reinterpretar as possibilidades de ruptura do Serviço Social, a elaboração de um novo currículo em 1982 e do Código de Ética de 1986, marcos que expressam a ruptura com o histórico tradicionalismo na profissão e o envolvimento desta com os interesses das classes subalternas.

O artigo em tela procura apresentar, a partir da leitura e reflexão junto às obras de Karl Marx e Antonio Gramsci, elementos relevantes que possam contribuir no debate dos fundamentos da ética para o Serviço Social.

Além da introdução, o estudo se divide fundamentalmente em dois pontos, o primeiro no qual abordou-se o debate sobre os fundamentos ético-políticos profissionais para o Serviço Social e a importância da incorporação de uma teoria revolucionária para ancorar a dimensão filosófica de um projeto profissional crítico. No segundo ponto expõe-se algumas

\footnotetext{
${ }^{3}$ Embora as obras gramscianas na América Latina remontem os anos de 1950, com a publicação das Cartas do Cárcere pela Ediciones Lautaro em Buenos Aires, sua inserção no Brasil foi atravessada por dois importantes obstáculos, a saber: a decretação do Al-5 (1968) e a então cultura dominante da esquerda nacional que era influenciada pelo "marxismo da Terceira Internacional". Logo, Simionatto (2011) evidencia que a recepção das ideias do marxista italiano no Brasil se deu, de uma forma geral, por dois grandes ciclos, no primeiro alinhamse as publicações da década de 1960, que compreendem os trabalhos de Carlos Nelson Coutinho, Leandro Konder, Michael Löwy e Otto Maria Carpeaux. Enquanto no segundo ciclo encontram-se as produções da metade das décadas de 1970 e 1980, período auge da produção teórica sobre o autor, tal ciclo ganha fôlego acompanhando a crise da autocracia, marcada em 1979 pela revogação do Al-5, com subsequente reabertura política e cultural no Brasil.
} 
aproximações às contribuições do pensamento de Marx e Gramsci sobre as relações sociais capitalistas e a dimensão da ética.

\section{Os Fundamentos Históricos e Ético-Políticos: o projeto profissional do Serviço Social e a necessidade da teoria revolucionária marxista e marxiana.}

Para além de uma "ciência da moral" (VÁZQUEZ, 2006), ou seja, uma teoria que explica o comportamento moral dos sujeitos; a ética pode ser entendida como a capacidade de agir conscientemente com base em escolhas de valor, projetar finalidades de valor e objetivá-las concretamente na vida social. É também caracterizada como uma mediação entre as esferas e dimensões da vida social situada em suas várias formas e expressão: a moral, a moralidade, ética e a ação ética como exercício de liberdade (BARROCO, 2003, p. 19).

São nas sociedades que as normas de comportamento são criadas e repassadas para seus membros, os quais por sua vez as reproduzem ou alteram segundo suas trajetórias. 0 agir do indivíduo em sociedade é guiado por uma moral ${ }^{4}$ que foi socialmente construída. Barroco (2009) coloca que o ato moral supõe sua adesão consciente e voluntária às normas e valores éticos pré-estabelecidos. Contudo, se reitera ainda, que nem sempre tal aceitação pode ser considerada como sinônimo de interiorização consciente e livre, pois muitas vezes apenas reproduz-se mecanicamente as normas sem uma reflexão crítica frente a elas.

O agir ético pode se expressar também na capacidade teleológica de construir tanto projetos individuais como coletivos, motivados pela finalidade de satisfazer suas necessidades individuais e coletivas. Quando há a elevação do ser singular, "eu", individual, ao ser genérico.

[...] os indivíduos sociais agem, segundo necessidades, sentimentos e projetos referidos à sua individualidade, ao mesmo tempo em que atuam como membros do gênero humano, daí suas aspirações, emoções, projeções possuírem um caráter humano-genérico (RAMOS, 2002, p. 82).

O projeto profissional, enquanto um projeto coletivo, não se resume à soma das individualidades, é uma construção coletiva que pode se dar em diferentes espaços: em fóruns de deliberações, espaços com participação democrática, com diferentes profissionais,

\footnotetext{
${ }^{4} \mathrm{~A}$ moral é entendida como conjunto de normas e costumes historicamente e socialmente construídos, uma mediação entre o indivíduo singular e sua dimensão social ou humano-genérica (BARROCO, 2009).
} 
partidos e matrizes ideopolíticas. "Os projetos societários estabelecem mediações com as profissões na medida em que ambos têm estratégias definidas em relação ao atendimento de necessidades sociais, com direções éticas e políticas determinadas (BARROCO, 2003, p. 66)

Um projeto profissional, enquanto autoimagem de uma profissão (NETTO, 1999), não é estático, está em constante movimento, possui uma relação intrínseca à realidade, é fruto das transformações culturais, econômicas e históricas vividas pelos sujeitos profissionais na sociedade, envolvendo elementos seja de sua formação profissional e indivíduo social, que das relações profissionais.

O projeto profissional coletivo e historicamente construído por uma categoria é um dos elementos que compõem a ética profissional, essa entendida como um modo particular de objetivação da vida ética, que tem como âmbito de realização o modo de ser (ethos) da profissão, sua dimensão filosófica e a normatização profissionalmente construída (BARROCO, 2003). Deste modo, sua organicidade (maior ou menor) depende da coesão de seus agentes profissionais em torno de finalidades projetadas coletivamente. Daí a constante necessidade de construção de espaços coletivos de debates no interior da categoria, a fim de fortalecer e/ou refletir em torno do respectivo projeto profissional, elemento sempre dinâmico e histórico.

O Código de Ética profissional é um dos elementos sob o qual a ética profissional se objetiva. Trata-se de um "conjunto de valores e princípios, normas morais, direitos, deveres e sanções" (BARROCO, 2009, p. 176), orienta o comportamento individual das/dos profissionais, a relação com as demais categorias e instituições, população usuária e entidades. Apontando também para um "dever ser" da categoria.

Foi evidenciado também a importante presença de uma filosofia ou teoria social que sustenta o agir profissional, esta revela a forma como a/o profissional ler o mundo com o qual se depara no cotidiano, fundamenta o intervir, a partir dos seus valores éticos e morais.

Da mesma forma que a moral no âmbito do agir humano apresenta-se como uma mediação entre o singular e o universal (sociedade), a moral profissional se evidencia na ação profissional cotidiana, entre seus profissionais, e "no produto concreto da intervenção profissional." (BARROCO, 2009, p. 176). Tal moral profissional não é isenta dos processos da alienação presentes na sociabilidade capitalista, pois para além da formação estritamente 
profissional, as/os assistentes sociais estão inseridos na sociedade, têm suas visões de mundo condicionadas pela educação formal e informal, o senso comum, a família etc.

Vale ressaltar que no Serviço Social se tem a existência de tendências filosóficas tanto tradicionais e conservadoras, quanto revolucionárias. Na trajetória histórica da profissão, tais tendências contribuem para reprodução ou superação do status quo.

Atualmente pode-se afirmar que o Serviço Social brasileiro conta com um projeto profissional, configurado como uma direção social, ético e política vinculada a um projeto de transformação societária. Tal projeto profissional, chamado de Projeto Ético-Político (PEP), foi herança histórica do processo de "renovação" ${ }^{5}$ das bases tradicionais da profissão. ${ }^{6}$

Remonta dos anos de 1960 o processo de renovação do Serviço Social, momento em que a profissão começa a questionar sua prática e atuação, no sentido de romper com a histórica subalternidade e com os pressupostos do Serviço Social tradicional.

Nesse contexto destacam-se os Seminários de teorização da Associação Brasileira de Ensino de Serviço Social (ABESS) e do Comitê Brasileiro da Conferência Internacional de Serviço Social (CBCISS). Ao fazer um resgate histórico e crítico dos referidos seminários, Netto (2002) destaca os de Araxá (1967) e Teresópolis (1970) ainda sob a influência do positivismo e funcionalismo.

Os Códigos de Ética de 1965 e 1975 são expressões desse processo no interior da profissão. No Código de 1965 evidenciam-se ainda as influências dogmáticas da Igreja Católica (neotomismo), prevalecendo a visão abstrata do "homem", bem como da perspectiva desenvolvimentista; o Código de 1975 traz elementos das reflexões originarias dos seminários de Araxá e Teresópolis, reconhecendo já o Estado como gestor do "bem comum", reproduzindo um viés governamental (ABATH; MUSTAFA, 2006).

Importante ressaltar que foi a partir do Seminário de Araxá que deu-se início à erosão das bases do Serviço Social tradicional expresso também no surgimento chamado

\footnotetext{
${ }^{5}$ Vale observar a definição sugerida por Netto (2002). A saber: "Entendemos por renovação o conjunto de características novas que, no marco das constrições da autocracia burguesa, o Serviço Social articulou, à base do rearranjo de suas tradições e da assunção do contributo de tendência do pensamento social contemporâneo." (NETTO, 2002, p. 131).

${ }^{6}$ Como expressão jurídico-política de materialização do PEP têm-se principalmente o Código de Ética profissional (CONSELHO FEDERAL DE SERVIÇO SOCIAL, 1993), a Lei de Regulamentação da Profissão (BRASIL, 1993) e as Diretrizes Curriculares. Um outro marco importante para o Serviço Social no Brasil foi o seu reconhecimento, em 1987, enquanto área de produção de conhecimento por parte das agências de fomento à pesquisa.
} 
"Movimento de Conceituação". Netto (2002) observa que os elementos basilares que contribuíram com tal movimento foram externos à profissão, ligados ao contexto histórico vivido na América Latina dos anos 1950 a 1970, caracterizado pela generalização das Ditaduras Militares em praticamente todos os países do Cone Sul, desencadeado por uma política intervencionista e imperialista norte-americana, setores das classes subalternas e grupos sociais começaram a se questionar sobre o modelo de desenvolvimento capitalista e as alternativas para superação do "subdesenvolvimento".

Particularmente no Brasil, as/os profissionais começaram a se indagar sobre modalidades de intervenção mais voltadas às problemáticas macrossociais, à ordem burguesa e suas instituições e organizações governamentais, o próprio elenco de políticas do Welfare State; e os valores burgueses da "integração social". Tais críticas, segundo Netto (2002) tiveram como base a convergência de três vetores: 1) a revisão crítica frente às teorias das Ciências Sociais, com críticas ao funcionalismo, a neutralidade e superficialidade; 2) a aproximação ideopolítica de algumas instituições sociais, historicamente, vinculadas ao Serviço Social, como por exemplo setores progressistas da Igreja Católica, às alternativas críticas com a ordem capitalista; 3 ) o protagonismo do movimento estudantil.

Vale destacar que no Brasil, no âmbito do processo de renovação e crítica ao Serviço Social tradicional, houve também iniciativas de parte de setores da profissão que buscaram fazer um recurso à fenomenologia, através de "uma nova proposta" de Anna Augusta Almeida.

Tal proposta de "reatualização do conservadorismo" (NETTO, 2002), possui um caráter conservador, não incorpora às problemáticas da questão social de sua época, "recupera o que há de mais consagrado no tradicionalismo profissional: a herança psicossocial, a tendência à centralização nas dinâmicas individuais e o viés psicologizante." (NETTO, 2002, p. 245), reforçando assim traços conservadores presentes nos Códigos de Ética 65 e 75.

A partir da década de 70, seguindo os movimentos pela redemocratização, em nível nacional e internacional, o Serviço Social brasileiro dá continuidade ao processo de aproximação à matriz marxista, como expresso no "Método de Belo Horizonte - BH" como ficou conhecido o Projeto da Escola de Serviço Social de Belo Horizonte da Universidade 
Católica de Minas Gerais (UCMG).

Importante marco histórico desse processo foi o III Congresso Brasileiro de Assistentes Sociais em 1979. Conhecido como "Congresso da Virada" em tal evento a categoria afirmou a defesa aos direitos sociais e setores subalternos da população.

Contudo o autor destaca também que tal primeira aproximação não foi isenta de equívocos, pois se tratava de um marxismo sem o recurso ao Marx e sob fortes influências de abordagens reducionistas e estruturalistas (baseadas principalmente no marxismo de Althusser e nas concepções presentes na II e III Internacional).

Barroco (2003) afirma que dentre os equívocos do período, destaca-se o de querer transportar mecanicamente valores e concepções instituídos em situações revolucionárias para outros contextos. O que gerou na profissão processos como o de "deprofissionalização", associação do trabalho profissional ao trabalho voluntário militante, abnegado etc.

Tais equívocos serão posteriormente superados a partir de críticas ao marxismo vulgar, recurso às obras de Marx, e incorporação de importantes autores e teóricos marxistas, como Antônio Gramsci e György Lukács.

Em sua expressão teórica o PEP se enraíza no conjunto da produção de conhecimento do Serviço Social, que atualmente tem como marco hegemônico forte influência na teórica social crítica, especificamente na teoria marxista.

Foi em um contexto de rebeldia e ousadia da categoria profissional que se gestou um projeto que não se limitou a elencar e sinalizar normas de conduta para as/os assistentes sociais, mas que incorporou a sua dimensão deontológica uma dimensão ontológica e de transformação societária.

O Código de Ética de 1996 é norteado por escolhas teóricas que se fundamentam na teoria crítica do ser social, esta sustentam a profissão em duas importantes dimensões: a teleológica e a ontológica. Para Abramides (2019):

A dimensão teleológica da profissão indica sua finalidade social na divisão sociotécnica do trabalho, nos espaços sócio-ocupacionais contraditórios, na relação capital-trabalho, com hegemonia das classes dominantes; se dirige ao enfrentamento da "Questão Social", que exige resistência e luta pelos direitos sociais. A dimensão ontológica pressupõe o horizonte da emancipação humana, que incide na compreensão da necessidade da revolução social para a superação da barbárie capitalista. Reafirmar essas duas dimensões pressupõe estabelecer 
mediações profissionais, com base na realidade sócio-histórica, nas esferas institucionais e nas esferas autônomas dos movimentos sociais (ABRAMIDES, 2019, p. 58).

$\mathrm{Na}$ dimensão político-organizativa, ancorada nos diferentes fóruns coletivos das entidades representativas do Serviço Social, O PEP se materializa nos Conselhos Federal e Estaduais (Conjunto CFESS/CRESS), na Associação Brasileira de Ensino e Pesquisa em Serviço Social (ABEPSS) e no Movimento Estudantil de Serviço Social (MESS). Todas essas dimensões (seja de formação ou de exercício profissional) se articulam no sentido de proporcionar uma organicidade e maturidade à profissão.

Entretanto, os dias atuais nunca foram tão desafiantes para o Projeto Ético-Político e a classe trabalhadora. Na conjuntura nacional vive-se um intenso acirramento das bases histórico-político sob as quais foi construído o referido projeto profissional.

As legislações sociais estão vivendo um processo articulado e programado de constantes inflexões. São "contrarreformas" de caráter autoritário e antidemocrático que alterar a Constituição Federal de $1988^{7}$, têm-se dessa forma verdadeiros retrocessos para sociedade brasileira, em especial para aqueles grupos que dependem do conjunto de seguridade social pública (saúde, previdência e assistência social, conforme o estabelecido nos Artigos 193/194 e 195 do Título VIII - Da Ordem Social).

Observa-se o desmantelamento das políticas sociais existentes e ataque frontal aos direitos sociais e trabalhistas, pode-se destacar a aprovação da Lei 13.467 de 13 de julho de 2017 (BRASIL, 2017), que altera a Consolidação das Leis do Trabalho. Nota-se ainda o reforço às medidas "pelo alto", como, por exemplo, as Emendas Constitucionais (EC) ${ }^{8}$ e Medidas Provisórias.

É importante entender que tal processo nacional não está dissociado de um movimento maior que se caracteriza pelo ressurgimento de grupos fascistas de extremos

\footnotetext{
${ }^{7}$ Pelo menos até 2017, um total de 99 emendas à Constituição Federal de 1988 já haviam sido aprovadas.

${ }^{8}$ Vale ressaltar a EC 95/2016, que instituiu um novo regime fiscal, medida inaudita que determina limite para os gastos da União para as próximas duas décadas (BRASIL, 2016) e a EC 103/2019 que efetiva uma contrarreforma no sistema previdênciário brasileiro, aumenta os anos de trabalho para acesso a aposentadoria tanto para homens quanto para mulheres (BRASIL, 2019).
} 
direitos em diferentes países e governos pelo mundo, como uma reação conservadora frente à crise orgânica ${ }^{9}$ do capital.

Vale destacar as vitórias de candidatos conservadores à presidência de países que ocupam uma posição estratégica mundialmente, como por exemplo Donald Trump em 2016 para os Estados Unidos da América, Matteo Salvini em 2018 (vice-primeiro-ministro) para Itália e Jair Bolsonaro em 2019 no Brasil; evidencia-se o crescimento de medidas reacionárias, como a xenofobia, o racismo e o revigoramento de medidas fascizantes em todo o mundo, no contexto da crise orgânica mundial, na qual, o neoliberalismo contribui decisivamente para intensificar a distância entre ricos e pobres.

Particularmente, no Brasil pode-se entender que a recente ascensão de grupos reacionários e direitistas ao poder, se explica também por elementos da própria constituição da burguesia nacional de caráter eminentemente conservador, escravagista, antidemocrática e antipopular. O atual governo evidencia todos esses elementos e ainda ressalta o seu caráter heteronômico, no qual a burguesia brasileira se "curva" ao neoliberalismo norte-americano.

Tais questões somadas aos "velhos" ataques no âmbito do exercício profissional (contratos de trabalhos precários e flexibilizados, subcontratação, pluriemprego, assédio moral, adoecimentos, desgaste físico e mental etc.) e da formação profissional (precarização do trabalho docente, cortes e contingenciamento de recursos para o ensino superior, "proliferação" e expansão do ensino superior na modalidade à distância - EAD etc.) trazem para a direção social do Serviço Social, e para classe trabalhadora, a necessidade de um maior fortalecimento teórico e ético-político de seus fundamentos.

Nesse sentido, corrobora-se com Yazbek (2009) ao destacar que se embora atualmente possa-se falar de uma hegemonia em torno da teoria marxista, vive-se em uma sociedade, que constantemente, há reafirmação de tendências de caráter neoconservador,

\footnotetext{
${ }^{9}$ A expressão "crise orgânica" ou crise de hegemonia foi cunhada por Gramsci e está presente em diversos de seus cadernos, com destaque para os Cadernos 3 e 13. Para o referido autor, a classe dominante para tornarse hegemônica precisa ser tanto "dominante" (das classes adversárias) quanto "dirigente" (das classes aliadas). Contudo, "Se a classe dominante perdeu o consenso, isto é não é mais 'dirigente', mas unicamente 'dominante', detentora da força coercitiva, isto significa que as grandes massas se destacaram das ideologias tradicionais, não acreditam mais no que antes acreditavam etc. A crise consiste assim, no fato que o velho morre e o novo não pode nascer: nesse interregno se verificam os fenômenos mórbidos mais variados (GRAMSCl, 2014d, p. 311). Assim, é no momento de crise orgânica que a classe dominante pode adotar medidas ultrarreacionárias no sentido restabelecer a hegemonia, como exemplo histórico pode-se destacar o fascismo.
} 
pautadas no fortalecimento de posturas preconceituosas, autoritárias e racistas, presentes na sociedade e também em parte dos profissionais, conforme sinalizado acima. No âmbito universitário, ressalta a autora, tem-se ainda o fortalecimento da teoria e ideologia pósmoderna e conservadora. O que revela a permanência de tensões e ambiguidades no quadro das matrizes teórico-metodológicas do Serviço Social nacional.

Concorda-se ainda com Santos (2007) ao sinalizar para existência de um pluralismo/sincretismo presente na profissão, bem como o peso do conservadorismo em sua constituição ideoteórica e histórica, sendo necessário uma maior atenção no sentido de não "superdimensionar" tal direção social, e sempre buscar fortalecer nos diferentes espaços (seja da formação que do exercício profissional) as bases concretas para sua materialização.

Realizar um resgate aprofundado junto às bases da teoria revolucionária marxista e marxiana torna-se um imperativo. Dessa forma, ver-se-á no próximo ponto, como que a leitura de algumas obras de Karl Marx e Antonio Gramsci podem contribuir para fundamentação filosófica do estudo dos fundamentos éticos do Serviço Social, fortalecendo suas bases críticas e revolucionárias.

\section{Aproximações à dimensão da ética no pensamento de Karl Marx e Antonio Gramsci}

A ética se manifesta na vida cotidiana do ser individual como "parte da práxis social" (BARROCO, 2009, p. 167), isto é, enquanto uma capacidade eminentemente humana que se expressa no agir cotidiano em sociedade, estando assim conectada à "base ontológica vida social" (BARROCO, 2009, p. 168) - o trabalho.

Mediante este, o ser social é capaz de projetar em seu pensamento uma finalidade a ser alcançada; objetivar/executar a atividade projetada por ele mesmo e, por fim, ter o controle, se apropriar daquilo que desenvolveu, como pertencente de si mesmo. O trabalho funda o ser social, o diferenciando do simples animal, contribui no processo de desenvolvimento de sua capacidade criativa e livre.

O ser social passa então a criar alternativas, o que por sua vez abre a possibilidade de escolhas e valoração no sentido de opção pelo que é considerado melhor, comparações entre o bom ou mau, bonito ou feio, correto ou incorreto, constituição dos juízos de valor a partir 
da avaliação do que é útil, inútil, válido ou não válido. Os valores e as alternativas expressam uma construção histórica e socialmente condicionada.

Mediante a capacidade emancipadora do trabalho, o ser social é dotado da possibilidade de construir sua própria história, sua emancipação enquanto resultado da sua ação. Contudo, as formas de (re)produção da vida social, construídas historicamente e socialmente pelos sujeitos, podem tanto realizar quanto negar as potencialidades emancipadoras do trabalho.

Na sociedade capitalista o trabalho assume uma forma essencialmente alienada, pautada na cisão entre o sujeito e o objeto, entre a projeção e o controle dos resultados sobre o que é projetado e executado. Isso se deve pela divisão social e técnica do trabalho em suas diversas manifestações e organizações de acordo com as exigências do capital, que tem se manifestado na história sob a forma de: taylorismo, fordismo, reestruturação produtiva, toyotismo; de modo a garantir cada vez mais a apropriação individual sob a forma de lucro e a socialização do trabalho, sem a devida reposição da força de trabalho gasta nesse processo. Dessa forma, a riqueza humana não é apropriada material e espiritualmente pelos indivíduos que a construíram (BARROCO, 2003, p. 34).

Essa organização de trabalho, baseada, na "exploração do homem pelo homem", transforma o ser humano, enquanto trabalhador, em mais uma mercadoria, um objeto. Assim, "o capital aliena o homem de si mesmo, o seu papel ativo, a sua atividade fundamental, aliena do mesmo modo o homem a respeito da espécie" (MARX, 2001, p. 116).

Sob tal assunto foi sinalizado algumas teses de Marx. Este afirma que a vida genérica, própria do ser humano, passa a ser um meio para se alcançar a vida individual, a consciência que os sujeitos têm de sua espécie altera-se por meio da alienação. Dessa forma cada trabalhador se vê perante as outras pessoas segundo o padrão e a relação que ele estabelece consigo mesmo:

[...] o trabalho é exterior ao trabalhador, ou seja não pertence à sua característica; portanto, ele não se afirma no trabalho, mas nega-se a si mesmo, não se sente bem, mas infeliz, não desenvolve livremente as energias físicas e mentais, mas esgota-se fisicamente e arruína o espírito. Por conseguinte, o trabalhador só se sente em si fora do trabalho, enquanto no trabalho se sente fora de si (MARX, 2001, p. 114). 
Na medida em que o trabalho alienado tira do sujeito o elemento da sua produção, retira também a sua vida genérica, a sua objetividade real como ser genérico, transformando em desvantagem a sua vantagem sobre o animal, alienação do homem em relação ao homem (MARX, 2001, p. 118).

A alienação pode manifestar-se também na legislação vigente, nas normas e costumes. Ao se entender o Estado como instituição necessária para manutenção da divisão de classes e preceitos capitalistas, compreende-se então que suas manifestações tendem a reproduzir tais pressupostos. Sob tal argumento vale ressaltar o debate de Marx sobre a crítica do direito.

Ainda nos seus 24 anos, o alemão, recém doutor em Filosofia, publicou anonimamente na Gazeta Renana, entre 25 de outubro de 03 de novembro de 1842, uma série de artigos, dentre os quais debatia sobre um projeto de lei da província de Reno, oeste da Alemanha, que passou a definir como crime a coleta de madeira por parte da população empobrecida, logo aquilo que era um direito consuetudinário de um povo passou a ser considerado um furto cabível de punições (MARX, 2017).

A instituição da propriedade privada, na natureza como mercadoria e sua transformação em "valor de troca" mobiliza diversas medidas, dentre elas um arsenal de legislações que possa impor junto à população proibições e punições e com isso garantir a manutenção da propriedade. Logo, "quando chama de furto de madeira um ato que nem chega a ser um delito de exploração de madeira, a lei mente e o pobre é sacrificado por uma mentira legal" (MARX, 2017, p. 81).

Afirma ainda:

Se todo atentado contra a propriedade, sem qualquer distinção, sem determinação mais precisa, for considerado furto, não seria furto também toda propriedade privada? Por meio de minha propriedade privada não estou excluindo todo e qualquer terceiro dessa propriedade? Não estou, portanto, violando seu direito à propriedade? (MARX, 2017, p. 82).

Interessante notar que em seu texto ainda como jovem jornalista, Marx precocemente realizou uma crítica aos valores da sociedade ao evidenciar que no mesmo momento em que o capital precisa assegurar a apropriação privada dos bens naturais ele 
precisa também expropriar todo um contingente de pessoas e para isso faz uso de legislações para assegurar os interesses dos proprietários, estando alheios às necessidades humanas.

Em outra obra de sua maturidade, o filósofo alemão aprofunda no estudo sobre a alienação e o fetiche, este último entendido como desdobramento prático da alienação, é definido como a alteração da percepção das relações entre os produtores (MARX, 1985). Dessa forma, as relações sociais assumem a forma de relação social entre coisas, entre os produtos do trabalho, ou seja, relações entre mercadorias. Assim, num sistema baseado na constante produção de mercadorias, as relações entre os indivíduos tornam-se coisificadas. O ser humano tende a perder a compreensão histórica da realidade, da própria dimensão da totalidade, uma parte da relação social passa a ser considerada o todo, altera-se assim a compreensão entre particularidade e totalidade. As relações sociais são naturalizadas.

Nessa relação, o sujeito desaparece frente ao objeto, este por sua vez, apresenta-se como sujeito, dá-se um processo de coisificação/reificação. Os objetos assumem o lugar da ação do sujeito humano, estes parecem "ganhar vida", enquanto o ser humano parece não ter mais o controle sobre a sua.

Marx (1985) enfatiza, no entanto, que esse caráter misterioso da mercadoria, ou seja, o fetichismo, não provê da coisa em si, de seu valor de uso, mas do produto das relações sociais práticas, da produção e distribuição, do modo de produção, isso significa que o fetiche não é inexorável:

[...] os trabalhos privados só atuam, de fato, como membros do trabalho social total por meio das relações que a troca estabelece entre os produtos do trabalho e, por meio dos mesmos, entre os produtores. Por isso, aos últimos aparecem as relações sociais entre seus trabalhos privados como o que são, isto é, não como relações diretamente sociais entre pessoas em seus próprios trabalhos, senão como relações reificadas entre as pessoas e relações sociais entre as coisas (MARX, 1985, p. 71).

Dessa forma, a adoção do modelo de produção centrado no trabalho associado, caracterizado por ser uma forma de organização de trabalho pautado no controle consciente e coletivo dos produtores sobre o processo de produção, tende a romper com a alienação entre o sujeito e o objeto. 
A partir da crítica da economia política, Marx faz uma reflexão ética acerca das relações sociais capitalistas, primadas na constante (re)produção de desvalores ${ }^{10} \mathrm{e}$ alienações, caracterizando-se pela incessante constituição de uma sociabilidade antiética. Contudo, como o próprio autor afirma, as relações sociais são socialmente produzidas, historicamente construídas, assim é possível ao ser social a construção de novas relações e valores humanos.

No âmbito do debate da ética, a liberdade assume uma dimensão central. Como expressão da práxis humana, a liberdade é entendida como "[...] capacidade de escolha consciente dirigida a uma finalidade" (BARROCO, 2010, p. 28) e mesmo "[...] capacidade prática de criar condições para realização objetiva das escolhas e para que novas escolhas sejam criadas" (BARROCO, 2010, p. 28).

A ética e a liberdade são categorias que se relacionam mutuamente. Ao possuir a capacidade de agir e transformar, de ampliar e criar novas alternativas, é possível ao ser um agir guiado por atitudes éticas, como a solidariedade, o altruísmo, o companheirismo etc.

Como isso, quer se dizer que é na vida em sociedade que o ser social, guiado por sua concepção de mundo, pode materializar seu agir e sua postura moral-ética. Como elementos constituintes e imprescindíveis das objetivações éticas, Barroco (2010) elenca: o sujeito éticomoral, a moral, o conhecimento ético e a práxis ético-política.

E mesmo diante da hegemonia do capital e sua concepção alienada e individualista de mundo, é possível ao ser social certa mobilidade de ação, no sentido da luta pelo fortalecimento de uma contra-hegemonia por parte de grupos e classes subalternas. “É em tal espaço de mobilidade política que é possível ao ser social-ético fazer escolhas políticas pautadas na defesa da liberdade do coletivo" (BARROCO, 2010, p. 64).

Embora o espaço da vida cotidiana seja essencialmente alienador, pois se move tomando como critério a utilidade prática das ações, sua dinâmica pragmática e imediatista,

\footnotetext{
${ }^{10}$ Conforme Heller (2004, p. 50) pode-se considerar valor tudo aquilo que, em qualquer das esferas e em relação com a situação de cada momento, contribua para o enriquecimento daqueles componentes essenciais, a autora define ainda que os componentes da essência humana são: o trabalho, a sociabilidade, a universalidade, a consciência e a liberdade. Assim, desvalor é tudo o que direta ou indiretamente rebaixe ou inverta o nível alcançado no desenvolvimento de um determinado componente essencial.
} 
não priorizando a reflexão e teorização dos fenômenos sociais; não significa que o cotidiano seja ontologicamente alienado (BARROCO, 2003).

Sendo assim, a alienação coexiste com elementos da práxis emancipadora, num movimento de afirmação e negação das potencialidades e possibilidades humanas; de criação e perda relativa de valores; de reprodução da singularidade alienada e da genericidade emancipadora (BARROCO, 2003, p. 36). Logo, a ética, a política, a arte, a filosofia e a cultura, estão entre as mediações que podem contribuir com o processo de elevação do ser humano individual ao ser humano genérico.

A dimensão da produção capitalista para sua (re)produção cria mecanismos para garantir seu desdobramento na estrutura social como um todo, implicando assim na formação de novas sociabilidades. Sobre tal argumento o marxista italiano Antonio Gramsci ${ }^{11}$ destaca a relação entre a estrutura produtiva/econômica e a constituição moral da classe trabalhadora.

No Quaderno 22 (V)1934 - Americanismo e fordismo Gramsci (2014c) analisa brilhantemente o complexo processo de formação de "novo modo de viver" mais adequado a uma nova racionalização industrial e fabril.

\begin{abstract}
Na América a racionalização do trabalho e a proibicionismo são inegavelmente conectados: as investigações dos industriais sobre a vida íntima dos operários, os serviços de inspeções criados por algumas agências para controlar a "moralidade" dos operários são necessidades do novo método de trabalho. (...) As iniciativas "puritanas" tem apenas o fim de conservar, fora do trabalho, um certo equilíbrio psico-físico que impressa o colapso fisiológico do trabalhador, espremido pelo novo método de produção. Esse equilíbrio não pode ser que puramente exterior e mecânico, mas poderá transformar esse interior se esse for proposto pelo mesmo trabalhador e não imposto pelos de fora, por uma nova formar de sociedade, com meios apropriados e originais (GRAMSCl, 2014c, p. 2165-2166, tradução nossa).
\end{abstract}

Se por um lado o Estado e mesmo um "corpo de inspetores" controlam a vida social (como por exemplo, o consumo de álcool fora do trabalho) e sexual do(a) trabalhador(a); por outro lado são criados mecanismos de persuasão para convencer a classe trabalhadora, como

\footnotetext{
${ }^{11}$ No âmbito dos estudos marxistas e marxianos, Gramsci si apresenta como um dos autores mais pesquisados em todo o mundo, sendo considerado pelo historiador Eric J. Hobsbawm como o teórico mais original do marxismo ocidental. Suas contribuições são relacionadas seja aos estudos e análises originais e inovadoras, seja a sua postura política no interior do Partido Comunista Italiana (PCI). No tocante a sua obra mais conhecida, os Quaderni del cárcere, Alvaro Bianchi (2018) sinaliza para importância de reconhecer o caráter inacabado, fragmentário e provisório de suas formulações, o que por outro lado, não invalida sua leitura, pelo contrário, reacende o imperativo de uma apropriação aprofundada e filológica do pensamento vivo de Antonio Gramsci.
} 
por exemplo altos salários. "Por isso a coerção deve ser sabiamente combinada com a persuasão e o consenso." (GRAMSCI, 2014c, p. 2171-2172, tradução nossa).

Dessa forma, diferentes mecanismos são adotados no sentido de constituir um novo indivíduo adaptado não apenas fisicamente, mas intelectual, cultural e sexualmente à produção fordista e taylorista.

Este complexo de compressões e coerções diretas e indiretas exercitadas sobre a massa obterá inegavelmente os resultados e surgirá uma nova forma de união sexual cuja monogamia e a estabilidade relativa aparentam ser um traço característico e fundamental (GRAMSCI, 2014c, p. 2171, tradução nossa).

Logo, a formação do "novo tipo humano" é essencial para constituição da hegemonia no interior da sociedade, tal constituição é condicionada pela racionalização do trabalho e da produção, espraiando-se por toda estrutura histórica, social, econômica e cultural de um país.

\footnotetext{
Existindo essas condições preliminares, já racionalizadas pelo desenvolvimento histórico, foi relativamente fácil racionalizar a produção e o trabalho, combinando habilmente a força (destruição do sindicalismo operário de base territorial) com a persuasão (altos salários, benefícios sociais diversos, propaganda ideológica e política habilíssima) e conseguindo fazer girar toda vida do país sobre a produção. A hegemonia nasce da fábrica e não precisa para exercitar-se que de uma quantidade mínima de intermediários profissionais da política e da ideologia (GRAMSCl, 2014c, p. 2145-2146, tradução nossa).
}

A partir das palavras do marxista sardo pode se entender que para assegurar a hegemonia é necessária a estruturação de todo um complexo social, econômico, político, cultural e filosófico. A constituição do ser humano, dessa forma, não deve ser negligenciada.

Segundo Eleonora Florenza (2009) para Gramsci a formação individual não é uma questão residual, mas central. Foi na busca pela compreensão de "como nasce o movimento histórico sob a base da estrutura (GRAMSCI, 2014c, p. 1422, tradução nossa) que o marxista sardo se deparou com a necessidade de se debruçar sobre a "constituição política da subjetividade" (FLORENZA, 2009, p. 552, tradução nossa), contrapondo-se a uma visão meramente subjetivista e determinista.

Nessa linha, a referida autora evidencia o conceito molecular na obra gramsciana como: 
[...] fundação da conexão entre os elementos para uma teoria materialista da personalidade e o problema da constituição do sujeito político [...]. É o nexo corpomente na sua historicidade e, nas suas possibilidades de transformação, que o molecular condensa, transformando-se assim conceito fundante para a teoria materialista da formação da personalidade, para uma conexão racialmente imanente do processo de subjetivação (FLORENZA, 2009, p. 552).

Toda a obra de Gramsci se concentra sobre tais elementos, na construção da hegemonia, no Estado, no debate sobre os grupos dirigentes etc. Tal complexo no seu movimento contraditório perpassa pela transformação molecular, em outras palavras, material-moral.

O desenvolvimento do partido em Estado reage sob o partido e o pede uma continua reorganização e desenvolvimento, assim como o desenvolvimento do partido e do Estado em concepção com o mundo, isto é em transformação total e molecular (individual) dos modos de pensar e operar, reage sob o Estado e o partido, obrigando-o a reorganizar-se continuamente e colocando para eles novos e originais problemas a resolver (GRAMSCl, 2014b, p. 1947, tradução nossa).

O marxista sardo ressalta assim a importância de uma reforma intelectual e moral do sujeito como o dever do "moderno Príncipe" (partido), associada assim a uma reforma econômica, pois "o programa de reforma econômica é o modo concreto sob o qual se apresenta cada reforma intelectual e moral" (GRAMSCI, 2014b, p. 1561)

Assim, no processo de formação de uma "vontade coletiva nacional-popular", enquanto "consciência ativa da necessidade histórica", o partido tanto organizador que "expressão ativa e operante", contribuindo para a constituição de uma:

[...] força permanente organizada e há muito tempo preparada, que se pode fazer avançar quando se julga que situação é favorável (e só é favorável na medida em que esta força exista e seja dotada de ardor combativo). Por isso, a tarefa essencial consiste em dedicar-se de modo sistemático e paciente a formar esta força, desenvolvê-la, torná-la cada vez mais homogênea, compacta e consciente de si (GRAMSCl, 2014b, p. 1588).

Destarte, Simionatto (2011) ressalta dimensão da cultura é para Gramsci uma ferramenta de emancipação política, pois "a partir dela, criam-se possibilidades de tomada de consciência em relação a problemas e situações comuns vividas pelos diferentes sujeitos sociais." (SIMIONATTO, 2011, p. 36). 
Pode-se assim dizer que a teoria comunista sardo possibilita ao Serviço Social “interrogar-se sobre questões relativas às instâncias estrutural e superestrutural, com reflexões não somente a respeito da esfera econômica, mas também política, ideológica e cultural" (SIMIONATTO, 2011, p. 25), realizando dessa forma uma mediação entre a necessidade da construção de um processo revolucionário e a ética, como uma dimensão estratégica fundamental.

Outro elemento importante do pensamento de Gramsci refere-se à adoção do termo marxismo como uma "filosofia da práxis", entende-se que tal escolha foi motivada não somente pela necessidade de "burlar" a censura vivida no cárcere, mas principalmente, para fazer uma revisão e interpretação crítica aos equívocos ligado ao II Internacional.

Em relação à tal tendência, Gramsci entende ser necessária a superação do viés reducionista, que ressalta principalmente a dimensão da sociologia da história e da política, centrado nas ciências sociais e no materialismo vulgar (LIGUORI; VOZA, 2009, p. 315).

Para Liguori e Voza (2009) o termo "filosofia da práxis" reflete uma nova filosofia original e independente das outras. Não como o mero sinônimo do termo "marxismo", mas uma posição contrária ao determinismo positivista e ao fatalismo materialista. É recorrendo às obras de Karl Marx, em particular ao Manifesto do Partido Comunista, que Gramsci vê nessa filosofia mais do que uma ciência, mas uma coincidência de "ciência-ação" (LIGUORI; VOZA, 2009, p. 313).

O conceito vontade assume uma centralidade no debate da "filosofia da práxis", pois envolve a dimensão do agir político coletivo, em especial da organização política das classes subalternas. Não é à toa que Gramsci afirma ser o partido político "a primeira célula na qual se sintetizam germes de vontade coletiva." (GRAMSCI, 2014b, p. 1558).

Em síntese, por filosofia da práxis se entende:

Teorização de uma relação humana que, no teorizar, exprime e organiza uma vontade de transformação, tornando-se práxis em si mesma. Contraria então o materialismo filosófico, a filosofia da práxis não concebe a matéria como um dato, mas - e essa é a ortodoxia gramsciana - como uma produção histórica da relação homem-matéria (LIGUORI; VOZA, 2009, p. 313). 
Logo, tal perspectiva não exclui a história ético-política. Enquanto momento de construção de hegemonia é assim "essencial na sua concepção estatal e na valorização do fato cultural, da atividade cultural, de uma fronte cultural como necessária do mesmo modo que as dimensões meramente econômicas e políticas (GRAMSCI, 2014a, p. 1224).

Tal reflexão sinaliza para a necessidade de entender da vida singular e particular de cada indivíduo como um espaço, em potencial, de agir político e eticamente. Com essa afirmação não se quer cair no equívoco de reduzir toda a análise ao indivíduo, mas ao contrário, entender o processo de formação de sua consciência como ser humano que interioriza a vida, mas que também a procura coletiva e politicamente transformá-la.

\section{Considerações Finais}

Defrontou-se com um contexto no qual os estados nacionais são capturados para responder aos interesses do capitalismo em crise, que não se demonstra mais compatível com reformas progressistas e com políticas sociais minimamente estruturadas, retomando ao nível mundial posturas de caráter ultraconservador e fascista.

Os dias hodiernos nunca foram tão desafiantes para o Projeto Ético-Político e a classe trabalhadora. Na conjuntura nacional vive-se um intenso acirramento das bases históricopolítico sob as quais foi construído este projeto profissional.

No referido estudo procurou-se realizar uma análise bibliográfica de obras de Karl Marx e Antonio Gramsci tendo como central evidenciar as contribuições de cada autor para os fundamentos da ética.

Diferentemente de algumas leituras equivocadas, identificou-se que o tema da ética assume uma importância tanto nas reflexões marxianas quanto marxistas. A partir da crítica da economia política, Karl Marx faz uma reflexão ética acerca das relações sociais capitalistas, que pautadas na constante (re)produção de desvalores e alienações, se caracterizam por serem essencialmente antiética, pois privilegiam o individualismo, a propriedade privada e a exploração.

Tal evidência é também notada nas reflexões de Gramsci. Na luta contraditória pela constituição da hegemonia, da formação do partido político revolucionário a dimensão moral, 
sexual e cultural precisam estar conectadas com as dimensões econômicas e políticas. Para se consubstanciar na realidade concreta, o modo capitalista precisou criar mudanças não apenas econômicas e políticas, mas também moleculares interferindo na cultura, na moral, na vida do ser social como um todo.

Dessa forma, ao ressaltar o marxismo como "filosofia da práxis", o comunista sardo reafirma dois pontos fundamentais para o partido político, são a reforma intelectual e moral, bem como a formação de uma vontade coletiva nacional-popular como central na dimensão do agir político coletivo de organização da classe trabalhadora.

\section{Referências}

ABATH, E. M. ; MUSTAFA, M. A. M. Notas introdutórias. In: GRUPO DE ESTUDOS E PESQUISAS SOBRE ÉTICA. Coletânea códigos de ética profissional do (a) assistente social. 2. ed. Recife: CTC, 2006.

ABRAMIDES, M. B. C. O projeto ético-político do serviço social brasileiro: ruptura com o conservadorismo. São Paulo: Cortez, 2019.

BARROCO, M. L. S. Ética e serviço social: fundamentos ontológicos. 2. ed. São Paulo: Cortez, 2003.

BARROCO, M. L. S. Fundamentos éticos do serviço social. In: CONSELHO FEDERAL DE SERVIÇO SOCIAL. Serviço social: direitos sociais e competências profissionais: unidade III. Brasília: CFESS, 2009. v. 1.

BARROCO, M. L. S. Ética: fundamentos sócio-históricos. 3 ed. São Paulo: Cortez, 2010.

BIANCHI, A. O laboratório de Gramsci: filosofia, história e política. 2. ed. Porto Alegre: Editora Zouk, 2018.

BRASIL. Emenda Constitucional no 95, de 15 de dezembro de 2016. Altera o Ato das Disposições Constitucionais Transitórias, para instituir o Novo Regime Fiscal, e dá outras providências. Brasília, DF: Presidência da República, 2016. Disponível em: http://www.planalto.gov.br/ccivil_03/constituicao/emendas/emc/emc95.htm. Acesso em: 9 jun. 2020.

BRASIL. Emenda Constitucional no 103, de 12 de novembro de 2019. Altera o sistema de previdência social e estabelece regras de transição e disposições transitórias. Brasília, DF: Presidência da República, 2019. Disponível em: http://www.planalto.gov.br/ccivil_03/constituicao/emendas/emc/emc103.htm. Acesso em: 5 jun. 2020. 
BRASIL. Lei no 8.662, de 7 de junho de 1993. Dispõe sobre a profissão de Assistente Social e dá outras providências. Brasília: Presidência da República, 1993. Disponível em: http://www.planalto.gov.br/ccivil_03/leis//8662.htm. Acesso em: 5 jun. 2020.

BRASIL. Lei no 13.467, de 13 de julho de 2017. Altera a Consolidação das Leis do Trabalho (CLT), aprovada pelo Decreto-Lei $n=5.452$, de 1 으 de maio de 1943, e as Leis $n \cong 6.019$, de 3 de janeiro de 1974, 8.036, de 11 de maio de 1990, e 8.212, de 24 de julho de 1991, a fim de adequar a legislação às novas relações de trabalho. Brasília, DF: Presidência da República, 2017. Disponível em: http://www.planalto.gov.br/ccivil_03/_ato20152018/2017/lei/l13467.htm. Acesso em: 6 jun. 2020.

BRAVO, M. I. S. et al. O protagonismo da ABESS/ABEPSS na virada da formação profissional em Serviço Social. In: SILVA, M. L. O. (org.). Congresso da virada e o Serviço Social hoje: reação conservadora, novas tensões e resistências. São Paulo: Cortez Editora, 2019.

CONSELHO FEDERAL DE SERVIÇO SOCIAL. Resolução CFESS no 273/93 de 13 de março de 93. Institui o Código de Ética Profissional dos Assistentes Sociais e dá outras providências. Brasília: CFESS, 1993. Disponível em: http://www.cfess.org.br/arquivos/resolucao_27393.pdf. Acesso em: 2 jun. 2020.

FLORENZA, L. M. In: LIGUORI, G.; VOZA, P. A cura di Dizionario Gramsciano 1926-1937. Roma: Ed. Carocci, 2009.

GRAMSCI, A. Quaderno 10 (XXXIII) 1932-1935: la filosofia di Benedetto Croce. In: GRAMSCI, A. Quaderni del carcere: volume secondo, quaderni 6-11. Torino: Giulio Einaudi editore, 2014a.

GRAMSCI, A. Quaderno 13 (XXX) 1932-1934. Noterelle sulla politica del Machiavelli. In: GRAMSCl, A. Quaderni del carcere: volume terzo, quaderni 12-29 (1932-1935). Torino: Giulio Einaudi editore, 2014b.

GRAMSCI, A. Quaderno 22 (V) 1934. Americanismo e fordismo. In: GRAMSCI, A. Quaderni del carcere: volume terzo, quaderni 12-29 (1932-1935). Torino: Giulio Einaudi editore, 2014c.

GRAMSCl, A. Quaderno 3 (XX) 1930 (Miscellanea). In: GRAMSCI, A. Quaderni del carcere: volume primo, quaderni 1-5 (1929-1932). Torino: Giulio Einaudi editore, 2014d.

HELLER, A. O cotidiano e a história. 7. ed. São Paulo: Paz e Terra Filosofia, 2004.

LIGUORI, G.; VOZA, P. A cura di Dizionario Gramsciano 1926-1937. Roma: Ed. Carocci, 2009.

MARX, K. Manuscritos econômicos-filosóficos. São Paulo: Editora Martin Claret, 2001.

MARX, K. O capital: crítica da economia política. 2. ed. São Paulo: Nova Cultura, 1985.

MARX, K. Os despossuídos: debates sobre a lei referente ao furto de madeira. São Paulo: Boitempo, 2017. 
NETTO, J P. A construção do Projeto Ético-Político do Serviço Social. Brasília: Cead, 1999.

NETTO, J. P. Ditadura e Serviço Social: uma análise do Serviço Social no Brasil pós-64. 6. ed. São Paulo: Cortez, 2002.

QUIROGA, C. Invasão positivista no marxismo: manifestações no ensino da metodologia do Serviço Social. São Paulo: Cortez Editora, 1991.

RAMOS, S. R. A construção de projetos coletivos: refletindo aspectos do projeto profissional do serviço social. Temporalis, Brasília, ano 3, n. 5, jan./jun. 2002.

SANTOS, J. S. Neoconservadorismo pós-moderno e Serviço Social brasileiro. São Paulo: Cortez, 2007.

SIMIONATTO, I. As abordagens marxistas no estudo dos fundamentos no Serviço Social. In: GUERRA, Y.; LEWGOY, A. M. B.; MOLJO, C. B.; SERPA, M.; SILVA, J. F. S. Serviço Social e seus fundamentos: conhecimento e crítica. Campinas: Papel Social, 2018.

SIMIONATTO, I. Gramsci: sua teoria, incidência no Brasil, influência no Serviço Social. 4. ed. São Paulo: Cortez, 2011.

VÁZQUEZ, A. S Ética. 28. ed. Rio de Janeiro: Civilização Brasileira, 2006.

YAZBEK, M. C. Os fundamentos históricos e teórico-metodológicos do Serviço Social brasileiro na contemporaneidade. In: CONSELHO FEDERAL DE SERVIÇO SOCIAL. Serviço Social: direitos sociais e competências profissionais. Brasília: CFESS/ABEPSS, 2009. 